\title{
SOLUSI PERSAMAAN DIFUSI PADA LARUTAN GULA DENGAN METODE BEDA HINGGA
}

\author{
Dedek Noviyani, Yundari, Yudhi
}

\section{INTISARI}

\begin{abstract}
Difusi merupakan peristiwa berpindahnya suatu zat dalam pelarut dari bagian berkonsentrasi tinggi ke bagian berkonsentrasi rendah. Difusi dapat dinyatakan dalam bahasa matematika yaitu persamaan difusi yang merupakan persamaan diferensial parsial. Contoh sederhana dari difusi adalah pemberian gula pada air tawar yang lambat laun menjadi manis. Konsentrasi larutan gula dipengaruhi oleh banyaknya air dan waktu yang diperlukan untuk terdifusinya larutan gula. Tujuan penelitian ini adalah menyelesaikan persamaan difusi pada larutan gula dengan metode beda hingga, yaitu mendiskritisasi turunan sehingga menjadi suatu sistem persamaan linier, kemudian sistem persamaan linier yang terbentuk diselesaikan. Hasil penelitian ini menunjukkan bahwa semakin lama waktu difusi yang dilakukan maka konsentrasi larutan gula semakin rendah.
\end{abstract}

Kata kunci: Persamaan Difusi, Persamaan Diferensial Parsial, Turunan Numerik, Metode Beda Hingga.

\section{PENDAHULUAN}

Difusi menggambarkan proses bertambah luasnya areal penyebaran polutan yang disebabkan oleh gerakan acak molekul-molekul polutan [1]. Persamaan difusi adalah persamaan diferensial parsial yang merupakan persamaan yang menggambarkan berpindahnya suatu zat dalam pelarut dari bagian berkonsentrasi tinggi ke bagian yang berkonsentrasi rendah [2]. Persamaan diferensial parsial dapat diselesaikan secara analitik maupun numerik. Salah satu metode numerik yang bisa digunakan untuk menyelesaikan persamaan diferensial parsial adalah metode beda hingga yang dalam penerapannya mengubah persamaan diferensial parsial menjadi bentuk sistem persamaan linier.

Penelitian ini menganalisis solusi persamaan difusi pada larutan gula dengan metode beda hingga. Langkah-langkah yang dilakukan dalam penelitian ini yang pertama adalah mendiskritisasi persamaan difusi pada larutan gula dengan menggunakan turunan numerik. Selanjutnya hasil diskritisasi dibentuk pola iterasi untuk memperoleh sistem persamaan linier. Kemudian sistem persamaan linier diselesaikan sehingga menghasilkan solusi persamaan difusi pada larutan gula.

\section{PERSAMAAN DIFUSI PADA LARUTAN GULA}

Diberikan larutan gula dengan konsentrasi tinggi sebesar $C_{0}$ ditempatkan dalam sebuah wadah persegi. Ketinggian larutan gula dari dasar wadah adalah $h$. Kemudian dengan sangat hati-hati air dituangkan ke atas larutan gula pekat sampai ketinggian $L$ [3]. (Gambar 1)

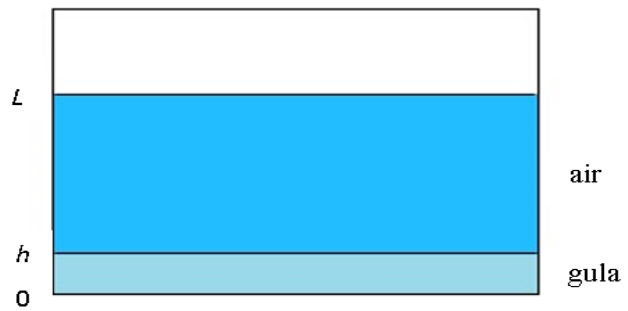

Gambar 1. Model percobaan difusi pada larutan gula

Misalkan $C(y, t)$ adalah konsentrasi larutan gula pada waktu $t$ dengan ketinggian $y$. Konsentrasi larutan gula pada waktu $t=0$ adalah

$$
C(y, 0)=\left\{\begin{array}{cc}
C_{0}, & 0<y \leq h \\
0, & h<y<L
\end{array} .\right.
$$


Laju penyebaran larutan gula berdasarkan Hukum Fick adalah

dengan syarat-syarat batas

$$
\frac{\partial C}{\partial t}=D \frac{\partial^{2} C}{\partial y^{2}} \leftrightarrow C_{t}=D C_{y y}, \quad 0<y<L,
$$

$$
\begin{aligned}
& \frac{\partial C}{\partial y}(0, t)=0, \quad y=0, t>0, \\
& \frac{\partial C}{\partial y}(L, t)=0, \quad y=L, t>0 .
\end{aligned}
$$

Pada penelitian ini diasumsikan bahwa difusi gula terjadi secara seragam sepanjang koordinat-x, sehingga konsentrasi larutan gula hanya merupakan fungsi yang tergantung terhadap $y$ dan $t$.

\section{METODE BEDA HINGGA}

Deret Taylor merupakan dasar untuk menyelesaikan masalah dalam metode numerik. Jika sukusuku deret Taylor tidak berhingga banyaknya, maka deret Taylor dipotong sampai suku tertentu. Deret Taylor yang dipotong sampai suku orde ke- $n$ dinamakan deret Taylor terpotong dan dinyatakan dalam bentuk [4]

$$
f(x)=f\left(x_{0}\right)+\frac{\left(x-x_{0}\right)}{1 !} f^{\prime}\left(x_{0}\right)+\frac{\left(x-x_{0}\right)^{2}}{2 !} f^{\prime \prime}\left(x_{0}\right)+\ldots+\frac{\left(x-x_{0}\right)^{n}}{n !} f^{(n)}\left(x_{0}\right)+R_{n}(x),
$$

yang dalam hal ini $R_{n}(x)$ disebut galat

$$
R_{n}(x)=\frac{\left(x-x_{0}\right)^{(n+1)}}{(n+1) !} f^{(n+1)}(c), \quad x_{0}<c<x .
$$

Rumus turunan numerik untuk tiga hampiran yaitu hampiran beda mundur, hampiran beda maju dan hampiran beda pusat diturunkan dengan menggunakan bantuan deret Taylor. Misalkan diberikan nilai-nilai $x$ di $x_{0}-h, x_{0}$ dan $x_{0}+h$, serta nilai fungsi untuk nilai-nilai $x$ tersebut. Titik-titik yang diperoleh adalah $\left(x_{-1}, f_{-1}\right),\left(x_{0}, f_{0}\right)$ dan $\left(x_{1}, f_{1}\right)$ yang dalam hal ini $x_{-1}=x_{0}-h$ dan $x_{1}=x_{0}+h$ dengan $h$ adalah jarak. Terdapat tiga hampiran dalam menghitung nilai $f^{\prime}\left(x_{0}\right):$ [5]

1. Hampiran beda hingga mundur (backward finite difference)

$$
f^{\prime}\left(x_{0}\right)=\frac{f\left(x_{0}\right)-f\left(x_{0}-h\right)}{h}=\frac{f_{0}-f_{-1}}{h} .
$$

2. Hampiran beda hingga maju (forward finite difference)

3. Hampiran beda hingga pusat (center finite difference)

$$
f^{\prime}\left(x_{0}\right)=\frac{f\left(x_{0}+h\right)-f\left(x_{0}\right)}{h}=\frac{f_{1}-f_{0}}{h} .
$$

$$
f^{\prime}\left(x_{0}\right)=\frac{f\left(x_{0}+h\right)-f\left(x_{0}-h\right)}{2 h}=\frac{f_{1}-f_{-1}}{2 h} \text {. }
$$

\section{METODE BEDA HINGGA UNTUK MENENTUKAN SOLUSI PERSAMAAN DIFUSI PADA}

\section{LARUTAN GULA}

Pertama dilarutkan 250 gram gula ke dalam 125 gram air, sehingga konsentrasi gula pekat yang diperoleh adalah $C_{0}=0,667 \%$. Larutan gula pekat dimasukkan ke dalam akuarium dan diukur ketinggiannya, yaitu $h=0,011 \mathrm{~m}$. Kemudian air dituangkan secara perlahan ke atas permukaan larutan gula pekat, sehingga permukaan larutan gula pekat tidak banyak berubah. Tinggi air dari dasar akuarium adalah $L=0,058$ m. 
Penyelesaian persamaan difusi pada larutan gula dengan metode beda hingga dapat diselesaikan dengan langkah-langkah sebagai berikut

\section{Langkah 1}

Diskritisasi Persamaan (1) dengan menggunakan turunan numerik yaitu, beda maju dan beda pusat yang merupakan pengembangan dari deret Taylor.

Misalkan $C_{i, j}$ adalah konsentrasi larutan gula pada waktu ke $i$ dan ketinggian ke $j$. Turunan beda hingga maju untuk mencari turunan pertama $C$ terhadap $t$ di titik $i, j$ dengan $\Delta t=a$ adalah

$$
C_{t}=\frac{\partial C}{\partial t}=\frac{C_{i, j+1}-C_{i, j}}{a} .
$$

Turunan beda hingga pusat untuk mencari turunan kedua $C$ terhadap $y$ di titik $i, j$ dengan $\Delta y=b$ adalah

$$
C_{y y}=\frac{\partial^{2} C}{\partial y^{2}}=\frac{C_{i+1, j+1}-2 C_{i, j+1}+C_{i-1, j+1}}{b^{2}} .
$$

Substitusikan Persamaan (2) dan (3) ke Persamaan (1), sehingga diperoleh

$$
\begin{aligned}
C_{t} & =D C_{y y} \\
\frac{C_{i, j+1}-C_{i, j}}{a} & =D\left(\frac{C_{i+1, j+1}-2 C_{i, j+1}+C_{i-1, j+1}}{b^{2}}\right) \\
-C_{i, j} & =D\left(\frac{a C_{i+1, j+1}-a 2 C_{i, j+1}+a C_{i-1, j+1}}{b^{2}}\right)-C_{i, j+1} \\
C_{i, j} & =-\frac{D a C_{i+1, j+1}}{b^{2}}+\frac{D a 2 C_{i, j+1}}{b^{2}}+C_{i, j+1}-\frac{D a C_{i-1, j+1}}{b^{2}} \\
C_{i, j} & =-\frac{D a}{b^{2}} C_{i+1, j+1}+\left(1+\frac{2 D a}{b^{2}}\right) C_{i, j+1}-\frac{D a}{b^{2}} C_{i-1, j+1}
\end{aligned}
$$

dengan $i=1,2, \ldots, N$ dan $j=1,2, \ldots, N-1$.

\section{Langkah 2}

Membentuk suatu pola iterasi untuk $i=1,2, \ldots, 50$ pada Persamaan (4) sehingga terbentuk suatu sistem persamaan linier.

Misalkan:

$$
A=-\frac{D a}{b^{2}}, \quad B=1+\frac{2 D a}{b^{2}}, \quad E=-\frac{D a}{b^{2}},
$$

sehingga didapat

$$
C_{i, j}=A C_{i+1, j+1}+B C_{i, j+1}+E C_{i-1, j+1} .
$$

Untuk $i=1,2, \ldots, 50$ memberikan suatu sistem persamaan linier sebagai berikut

$$
\left.\begin{array}{cc}
i=1 & C_{1, j}=A C_{2, j+1}+B C_{1, j+1}+E C_{0, j+1} \\
i=2 & C_{2, j}=A C_{3, j+1}+B C_{2, j+1}+E C_{1, j+1} \\
\vdots & \vdots \\
i=49 & C_{49, j}=A C_{50, j+1}+B C_{49, j+1}+E C_{48, j+1} \\
i=50 & C_{50, j}=A C_{51, j+1}+B C_{50, j+1}+E C_{49, j+1}
\end{array}\right\}
$$


Sistem persamaan linier (5) dapat ditulis dalam bentuk matriks sebagai berikut

$$
\left(\begin{array}{c}
C_{1, j} \\
C_{2, j} \\
C_{3, j} \\
\vdots \\
C_{49, j} \\
C_{50, j}
\end{array}\right)=\left(\begin{array}{cccccc}
B & A & 0 & 0 & 0 & 0 \\
E & B & A & 0 & 0 & 0 \\
0 & E & B & A & 0 & 0 \\
\vdots & \vdots & \ddots & \ddots & \ddots & \vdots \\
0 & 0 & 0 & E & B & A \\
0 & 0 & 0 & 0 & E & B
\end{array}\right)\left(\begin{array}{c}
C_{1, j+1} \\
C_{2, j+1} \\
C_{3, j+1} \\
\vdots \\
C_{49, j+1} \\
C_{50, j+1}
\end{array}\right),
$$

dan dapat ditulis dalam bentuk

$$
\mathbf{C}_{j}=\mathbf{M C}_{j+1},
$$

dengan

$$
\mathbf{M}=\left(\begin{array}{cccccc}
B & A & 0 & 0 & 0 & 0 \\
E & B & A & 0 & 0 & 0 \\
0 & E & B & A & 0 & 0 \\
\vdots & \vdots & \ddots & \ddots & \ddots & \vdots \\
0 & 0 & 0 & E & B & A \\
0 & 0 & 0 & 0 & E & B
\end{array}\right) .
$$

\section{Langkah 3}

Untuk menyelesaikan Persamaan (1) maka digunakan beberapa asumsi sebagai berikut:

1. Kondisi batas $C(0, t)=C(L, t)=0$,

$$
t>0
$$

2. Kondisi awal $C(y, 0)=\left\{\begin{array}{c}C_{0} \\ 0\end{array}\right.$

$$
\begin{aligned}
& 0<y \leq h \\
& h<y<L
\end{aligned}
$$

3. $a=\frac{t}{N-1}=\frac{7}{50-1}=0,143$

4. $b=\frac{L}{(N-1)}=\frac{0,058}{50-1}=1,183 \times 10^{-3}$

Setelah mengetahui asumsi-asumsi yang diberikan, maka selanjutnya mencari solusi Persamaan (1) dengan kondisi awal dan kondisi batas yang diketahui. Substitusikan nilai $a$ dan $b$ yang telah diberikan ke Persamaan (4) sehingga diperoleh

$$
C_{i, j}=-\frac{0,143 D}{\left(1,183 \times 10^{-3}\right)^{2}} C_{i+1, j+1}+\left(1+\frac{2(0,143) D}{\left(1,183 \times 10^{-3}\right)^{2}}\right) C_{i, j+1}-\frac{0,143 D}{\left(1,183 \times 10^{-3}\right)^{2}} C_{i-1, j+1},
$$

dengan $i=1,2, \ldots, 50$.

Berdasarkan langkah 2, Persamaan (6) dapat dinyatakan ke dalam bentuk

$$
\mathbf{C}_{j}=\mathbf{M C}_{j+1} \text {. }
$$

Selanjutnya Persamaan (1) dengan kondisi awal dan kondisi batas yang diketahui dapat dicari dengan menyelesaikan Persamaan (7), yaitu

$$
\mathbf{C}_{j+1}=\mathbf{M}^{-1} \mathbf{C}_{j}
$$


dengan

$$
\mathbf{M}=\left(\begin{array}{cccccc}
2,225 & -0,613 & 0 & 0 & 0 & 0 \\
-0,613 & 2,225 & -0,613 & 0 & 0 & 0 \\
0 & -0,613 & 2,225 & -0,613 & 0 & 0 \\
\vdots & \vdots & \ddots & \ddots & \ddots & \vdots \\
0 & 0 & 0 & -0,613 & 2,225 & -0,613 \\
0 & 0 & 0 & 0 & -0,613 & 2,225
\end{array}\right)
$$

dan $C_{0}=0,667$ dan $D=5,998 \times 10^{-6}$ yang dilakukan secara iterasi untuk $j=1,2, \ldots, 49$. Solusi $\mathbf{C}_{j+1}$ untuk $i=1,2, \ldots, 50, j=1,2, \ldots, 49$ dapat dinyatakan dalam Tabel 1 berikut

Tabel 1. Nilai solusi $\mathbf{C}_{j+1}$

\begin{tabular}{|c|c|c|c|c|c|c|c|c|c|c|}
\hline $\mathbf{C}_{1}$ & $\mathbf{C}_{2}$ & $\mathbf{C}_{3}$ & $\mathbf{C}_{4}$ & $\mathbf{C}_{5}$ & $\ldots$ & $\mathbf{C}_{46}$ & $\mathbf{C}_{47}$ & $\mathbf{C}_{48}$ & $\mathbf{C}_{49}$ & $\mathbf{C}_{50}$ \\
\hline 0.667 & 0.467 & 0.359 & 0.295 & 0.254 & $\ldots$ & 0.072 & 0.071 & 0.071 & 0.070 & 0.069 \\
\hline 0.667 & 0.607 & 0.542 & 0.487 & 0.441 & $\ldots$ & 0.143 & 0.141 & 0.140 & 0.138 & 0.137 \\
\hline 0.667 & 0.649 & 0.620 & 0.587 & 0.554 & $\ldots$ & 0.211 & 0.209 & 0.207 & 0.205 & 0.202 \\
\hline 0.667 & 0.662 & 0.650 & 0.634 & 0.615 & $\ldots$ & 0.275 & 0.273 & 0.270 & 0.267 & 0.265 \\
\hline 0.667 & 0.665 & 0.661 & 0.654 & 0.644 & $\ldots$ & 0.335 & 0.332 & 0.329 & 0.326 & 0.323 \\
\hline$\vdots$ & $\vdots$ & $\vdots$ & $\vdots$ & $\vdots$ & $\ddots$ & $\vdots$ & $\vdots$ & $\vdots$ & $\vdots$ & $\vdots$ \\
\hline 0.667 & 0.667 & 0.667 & 0.667 & 0.667 & $\ldots$ & 0.549 & 0.546 & 0.543 & 0.540 & 0.536 \\
\hline 0.667 & 0.667 & 0.667 & 0.667 & 0.666 & $\ldots$ & 0.518 & 0.514 & 0.511 & 0.508 & 0.504 \\
\hline 0.667 & 0.667 & 0.667 & 0.666 & 0.665 & $\ldots$ & 0.481 & 0.477 & 0.474 & 0.470 & 0.467 \\
\hline 0.667 & 0.667 & 0.666 & 0.665 & 0.663 & $\ldots$ & 0.438 & 0.435 & 0.431 & 0.428 & 0.424 \\
\hline 0.667 & 0.667 & 0.665 & 0.662 & 0.657 & $\ldots$ & 0.390 & 0.386 & 0.383 & 0.379 & 0.376 \\
\hline 0.667 & 0.665 & 0.661 & 0.654 & 0.644 & $\ldots$ & 0.335 & 0.332 & 0.329 & 0.326 & 0.323 \\
\hline 0.667 & 0.662 & 0.650 & 0.634 & 0.615 & $\ldots$ & 0.275 & 0.273 & 0.270 & 0.267 & 0.265 \\
\hline 0.667 & 0.649 & 0.620 & 0.587 & 0.554 & $\ldots$ & 0.211 & 0.209 & 0.207 & 0.205 & 0.202 \\
\hline 0.667 & 0.607 & 0.542 & 0.487 & 0.441 & $\ldots$ & 0.143 & 0.141 & 0.140 & 0.138 & 0.137 \\
\hline 0.667 & 0.467 & 0.359 & 0.295 & 0.254 & $\ldots$ & 0.072 & 0.071 & 0.071 & 0.070 & 0.069 \\
\hline
\end{tabular}

Setelah diketahui nilai dari $\mathbf{C}_{j+1}$ maka didapat grafik seperti pada Gambar 2.

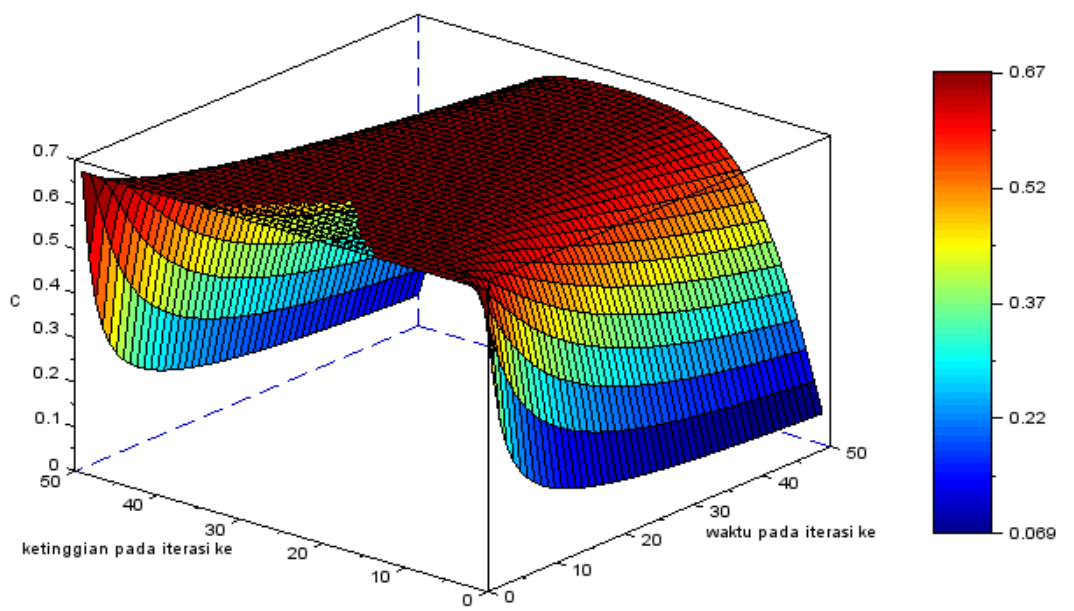

Gambar 2. Grafik solusi persamaan difusi pada larutan gula 
Gambar 2 merupakan grafik hasil solusi numerik Persamaan (1) dengan kondisi awal $C(y, 0)=C_{0}, 0<y \leq h, C(y, L)=0, h<y<L$ dan kondisi batas $C(0, t)=C(L, t)=0, t>0$. Berdasarkan Gambar 2, warna menunjukkan nilai-nilai dari konsentrasi gula pada waktu $t$ dan pada ketinggian $y$. Semakin lama waktu difusi yang dilakukan, warna pada grafik menunjukkan semakin berwarna merah tua akibatnya konsentrasi larutan gula semakin tinggi, sedangkan semakin berwarna biru tua akibatnya konsentrasi larutan gula semakin rendah.

\section{PENUTUP}

Berdasarkan hasil pembahasan dalam pencarian solusi persamaan difusi pada larutan gula dengan metode beda hingga diperoleh solusi numerik dari $C$ dengan semakin lama waktu difusi yang dilakukan maka konsentrasi larutan gula akan semakin rendah, sedangkan untuk ketinggian larutan gula pada $0<y \leq \frac{h}{2}$ konsentrasi larutan gula meningkat dan untuk ketinggian larutan gula pada $\frac{h}{2}<y<h$ konsentrasi larutan gula semakin menurun.

\section{DAFTAR PUSTAKA}

[1] Haryanto B. Pengaruh Pemilihan Kondisi Batas, Langkah Ruang, Langkah Waktu dan Koefisien Difusi pada Model Difusi. Aplika. 2008, 8:1-7.

[2] Laili AK dan Kusumastuti A. Keakuratan Solusi pada Persamaan Difusi menggunakan Skema Crank-Nicolson. Cauchy. 2014, 3:147-152.

[3] Trihandaru S, Widyayanti A, Rachmawati S, \& Toenlioe BS. Pemodelan dan Pengukuran Difusi Larutan Gula dengan Lintasan Cahaya Laser. Prosiding Pertemuan Ilmiah XXVI HFI Jateng \& DIY. Purworejo. 2012, 27-30.

[4] Munir R. Metode Numerik. Bandung: Informatika Bandung; 2015.

[5] Sasongko SB. Metode Numerik Dengan Scilab. Yogyakarta: CV. Andi Offset; 2010.

$\begin{array}{ll}\text { DEDEK NOVIYANI } & \begin{array}{l}\text { : Jurusan Matematika FMIPA UNTAN, Pontianak, } \\ \text { dedeknoviyani@ gmail.com }\end{array} \\ \text { YUNDARI } & \text { : Jurusan Matematika FMIPA UNTAN, Pontianak, } \\ & \text { yundari@ @ath.untan.ac.id } \\ \text { YUDHI } & \text { Jurusan Matematika FMIPA UNTAN, Pontianak, } \\ & \text { yudhi@ math.untan.ac.id }\end{array}$

